\title{
Shifting the birth weight paradigm
}

\section{Loae Khir and Raywat Deonandan}

\section{University of 0ttawa}

Birth weight is one of the most important indicators of overall infant health and likelihood of long-term survival. ${ }^{1}$ Traditionally, population health researchers have dichotomized this indicator, with the cut-off of "low birth weight" (LBW), defined as those less than 2,500 grams of mass, and "normal birth weight" for anything exceeding this cut-off. ${ }^{2}$ LBW has proven to be a useful statistic in a host of population health analyses, from indicating health system performance to predicting health trajectories for individual babies. However, a focus on LBW may have diverted our attention from various health concerns associated with other points along the birth weight spectrum. In this paper, we argue that more attention should be paid to those births at the other end of the weight scale, comprising the large for gestational age (LGA) births, which are commonly the result of fetal macrosomia.

The present focus on LBW is due in part to the welldemonstrated association between low birth weight and a host of deleterious outcomes. Such outcomes primarily revolve around fetal/neonatal mortality, impaired cognitive development, and chronic diseases in later life. ${ }^{3}$ These associations, coupled with $15.5 \%$ of annual births worldwide falling under the LBW category, ${ }^{1}$ caused the World Health Organization to declare the reduction of LBW as an important dimension of the Millennium Development Goal for reducing child mortality. Thus, a great deal of infant health research, specifically in the United States, has focused on the prevention of low birth weight, as per policies flowing from programs like Medicaid and the Special Supplemental Nutrition Program for Women, Infants and Children (WIC). ${ }^{4}$ Such policies aim to enhance the socioeconomic indicators of good health for lowincome women, who are seen as particularly vulnerable to delivering a LBW infant.
Over the past several decades, while attention has been focused on LBW issues, the prevalence of LGA births has crept higher. Fetal macrosomia, a term for infants born weighing greater than 4,000 grams, comprises up to $10 \%$ of total births in the United States. ${ }^{5}$ This rise may represent a public health crisis if it proves to be associated with other trending social phenomena, such as population obesity rates and nutritional deficits. Consequently, a re-tasking of the public health perception of birth weight may be in order.

Risks associated with LGA births include maternal risks for postpartum hemorrhage, perineal lacerations, increased rates of cesarean delivery, and higher maternal mortality; and infant risks of high blood sugar upon birth, shoulder dystocia, brachial plexus injuries, and asphyxia. ${ }^{6,7}$ Numerous long-term health consequences related to high birth weight are also documented. They include a predisposition for childhood and adult obesity, cardiovascular disease, diabetes, and metabolic syndrome. ${ }^{8}$

A major aspect of this paradigm shift must encompass an evaluation of current health technologies, as there is currently a lack of reliable diagnostic means for detecting macrosomia before birth. Clinical and ultrasound estimates are of limited reliability; studies suggest that when birth weight exceeds 4,500 grams, only $50 \%$ of fetuses weighed within $10 \%$ of the ultrasound estimate. ${ }^{9}$ Improved detection methods are an immediate priority, and may include more invasive, serological approaches.

In terms of immediate budgetary impact, the costs of associated health consequences and obstetric complications are significantly increased for LGA births, when compared to delivery of a normal weight fetus. ${ }^{10}$ Despite the lack of a thorough cost-effective analysis for reducing high fetal birth weight, similar to those that have resulted in legislation to reduce rates of low birth weight, preliminary cost-effective analyses outline increases in costs for 
E procedures associated with delivering a macrosomic fetus. Current practitioner options for high birth weight delivery are limited, but include labor induction, elective cesarean delivery, or expectant treatment. ${ }^{11}$ In the United States, the cost of vaginal delivery is $\$ 3,376$, while the cost of elective cesarean delivery is $\$ 5,200$; cesarean delivery with labor is $\$ 6,500$, and the lifetime cost of brachial plexus injury, one of the main obstetric complications associated with high birth weight delivery, is estimated at $\$ 1,000,000 .{ }^{10}$ Applied to nearly $10 \%$ of total births, these cost increases represent a substantial rise in overall health care spending.

Avoiding the public health burdens associated with increased rates of fetal macrosomia requires a shift in our current perspectives on what constitutes healthy birth weight. Primary health care, through reform of the contemporary prenatal care regimen, holds the greatest potential for inducing this paradigm shift. Incorporating a more balanced appreciation for both extremities of the birth weight spectrum would ultimately abate the plethora of acute and chronic health consequences associated with an increased incidence of fetal macrosomia. However, LBW births, for the time being, will remain the primary global concern, as policy and medical attention remains focused on the stated health and cost-effective benefits behind LBW interventions. But for high-income countries, like the United States, a greater consideration must be made of the probable impact of LGA births - particularly as obesity rates, linked with increasing LGA births, are projected to further rise over the next several decades.

\section{References}

1. United Nations Children's Fund and World Health Organization. Low birthweight: country, regional and global estimates. New York: UNICEF; 2004

2. Wilcox AJ. On the importance -and the unimportance- of birthweight. Int J Epidemiol. 2001;30(6):1233-41.

3. Horbar JD, Carpenter JH, Badger GJ, Kenny MJ, Soll RF, Morrow KA, et al. Mortality and neonatal morbidity among infants 501 to 1500 grams from 2000 to 2009. Pediatrics. 2012;129(6):1019-26.

4. Black SE, Devereux PJ, Salvanes KG. From the cradle to the labor market? The effect of birth weight on adult outcomes. QJ Econ. 2007;122(1):409-39.

5. Martin JA, Hamilton BE, Sutton PD, Ventura SJ, Menacker F, Kirmeyer S, et al. Births: final data for 2005. National vital statistics reports: from the Centers for Disease Control and Prevention, National Center for Health Statistics, National Vital Statistics System. 2007;56(6):1-103.

6. Richards M, Hardy R, Kuh D, Wadsworth MEJ. Birthweight, postnatal growth and cognitive function in a national UK birth cohort. Int J Epidemiol. 2002;31(2):342-8.

7. Stotland NE, Caughey AB, Breed EM, Escobar GJ. Risk factors and obstetric complications associated with macrosomia. Int J Gynaecol Obstet. 2004;87(3):220-6.

8. Gu S, An X, Fang L, Zhang X, Zhang C, Wang J, et al. Risk factors and longterm health consequences of macrosomia: a prospective study in Jiangsu Province, China. J Biomed Res. 2012;26(4):235-40.

9. Melamed N, Yogev Y, Meizner I, Mashiach R, Pardo J, Ben-Haroush A. Prediction of fetal macrosomia: effect of sonographic fetal weightestimation model and threshold used. Ultrasound Obstet Gynecol. 2011;38(1):74-81.

10. Herbst MA. Treatment of suspected fetal macrosomia: a cost-effectiveness analysis. Am J Obstet Gynecol 2005;193(3):1035-9.

11. Zamorski MA, Biggs WS. Management of suspected fetal macrosomia. Am Fam Physician. 2001;63(2):302-6.

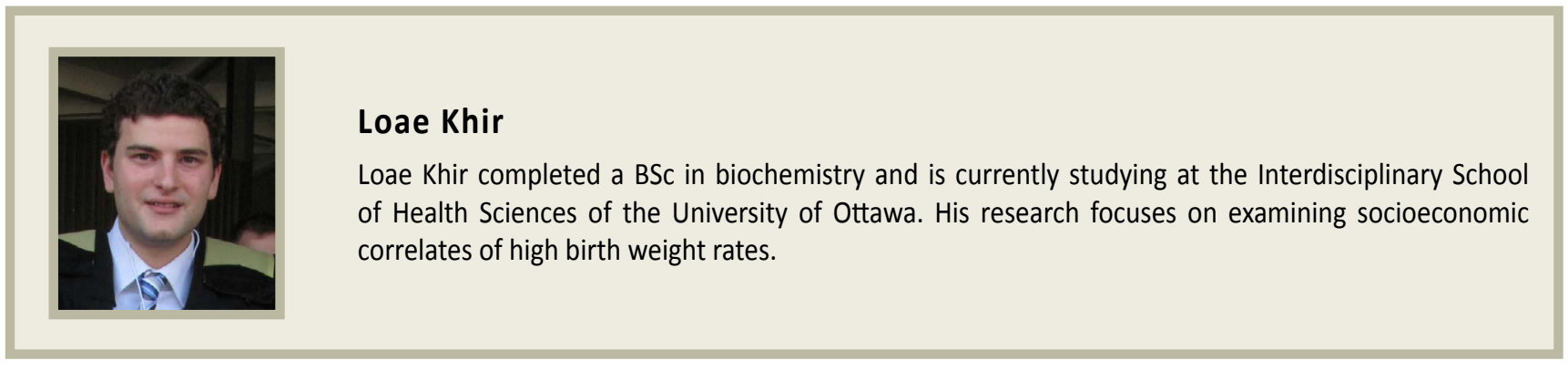

\section{Dr. Raywat Deonandan}

Dr Raywat Deonandan is an Epidemiologist and faculty member of the Interdisciplinary School of Health Sciences at the University of Ottawa. 